\title{
Conflitos conceituais nos estudos sobre meio ambiente
}

\author{
SAMUEL MURGEL BRANCO
}

A ANÁLISE OBJETIVA dos processos de transformação (ou de degradação) ambiental esbarra, atualmente, em uma série de divergências conceituais, com freqüência tendenciosas, a respeito, essencialmente, do que vem a ser natureza e do comportamento ideal do homem com relação a essa mesma entidade.

A questão essencial gira em torno do homem/natureza como relação de integração, de simples complementaridade, de estreita dependência ou de domínio absoluto. $O$ homem pertence à natureza? Pertenceu algum dia? Pertencerá no futuro? Em cada caso, quais as condiçôes básicas para que isso se realize? Qual o modelo que mais se coaduna com a relação real homem/natureza: o homem como seu participante; o homem como simples beneficiário natural; o homem como seu dependente? Poder-se-ia propor um modelo ideal e futuro de um entrosamento de feição tecnológica (e não como fruto de seleção natural) entre o homem e a natureza?

Muito provavelmente, os fundadores da ciência ecológica, seu conceito, sua abrangência e seus métodos de estudo jamais incluíram em seus objetivos essa questão marginal da influência que o homem, com suas técnicas, poderia exercer sobre a natureza, alterando as relaçōes ecológicas fundamentais. Humboldt, um dos seus fundadores, ao se defrontar com nascentes de petróleo na Venezuela, em 1799, pensou, apenas, no seu uso medicinal,("licor resinoso, aromático e medicinal..." ( Humboldt, 1991)) não suspeitando, nem de longe, que essa substância pudesse vir a ter, no futuro, um emprego tão amplo a ponto de alterar significativamente a composiçáo química da biosfera em todo o planeta e contribuindo para o que, já naquela época, era conhecido como efeito estufa, graças aos interessantes estudos do suíço De Saussure com suas caixas de vidro. O impacto do homem sobre o meio ambiente era caracterizado pela extração de minérios em algumas regiōes pontuais do mundo, pelo excesso de fumaças incômodas derivadas das lareiras domésticas em algumas grandes cidades e pelo eventual mau odor produzido por algum curtume ou matadouro. Nada que pudesse comprometer, de forma irreversível ou muito ampla, qualquer dos ecossistemas do Planeta. Incômodos eventuais, sim; danos irreparáveis não! 
Aliás, o homem não era, nessa época, considerado como elemento da natureza e sim como seu usuário. Inexistem, aparentemente, referências à sua posição nas cadeias tróficas ou a qualquer função relevante ou marginal deste com relação ao equilíbrio ecológico natural. Talvez os nativos americanos e alguns povos asiáticos tivessem uma noção mais correta - embora intuitiva - sobre essa relação, pois consideraram indispensável certo grau de reciprocidade nos benefícios auferidos da Terra. A filosofia grega, de que somos herdeiros, não fez esse tipo de consideração. A própria mola impulsora da evolução dos hominídeos foi - segundo Darwin - a seleção sexual e não a pressão generalizada do ambiente externo, dando a entender que a espécie humana não é tão dependente de um equilíbrio dos ecossistemas como são as outras espécies. Embora Darwin tenha, pela primeira vez, apontado de maneira conseqüente o homem como um ser animal, sujeito às mesmas características biológicas essenciais dos outros mamíferos, manteve, em certa medida, a sua independência ecológica.

Ora, se o homem não era, naquela época, considerado um componente interagente com a natureza, mas apenas um usuário compatível, causador de impactos negligenciáveis aos ecossistemas, é evidente que aqueles fundadores da ciência ecológica jamais teriam cogitado da futura existência de movimentos sociais ecológicos! É pouco provável, mesmo, que tenham se preocupado com as conseqüências ecológicas do aumento da população humana e os reflexos dessas consequiências sobre a própria sociedade. $\mathrm{O}$ próprio reverendo Malthus, ao prever que a Terra não poderia produzir alimentos para todos, vislumbrou uma limitação do crescimento populacional, mas não cogitou dos estragos que esse crescimento iria provocar sobre a natureza e a qualidade do ambiente.

O método de estudo ecológico utilizado pelos primeiros profissionais que se dedicaram a essa ciência - denominado hoje autoecológico - dificilmente poderia levar a considerações mais abrangentes sobre maciços impactos ambientais: os impactos atingem populações e só nessa dimensão podem tornar-se irreversíveis, provocar desequilíbrios ambientais ou extinção de espécies. As leis que regem a atuação do homem sobre os seres vivos são leis de grandes números, tal como as leis que regem a transmissão dos caracteres hereditários. É o império da estatística (e não mais da biologia) atuando sobre o microcosmos da genética e o macrocosmos da sinecologia. Foi, portanto, o estudo das populaçốes (dinâmica populacional, um campo da estatística) e o advento dos computadores que permitiram o aparecimento da sinecologia, com uma dimensão a mais no campo da ecologia, dimensão esta representada pela integração dos inúmeros fatores e circunstâncias ambientais em equilíbrio dinâmico e responsável pelo comportamento e sobrevivência de número significativo de espécimes vivos.

Esses conceitos e estudos aplicados ao conhecimento das relaçóes homem/ natureza e à previsão e à sustentação da sobrevivência humana constituem a abor- 
dagem mais recente, a qual, necessariamente, obrigou-se a incluir informações e conceitos oriundos da filosofia (da ética em particular) e da sociologia, assumindo, naturalmente, uma conotação política no sentido de procurar institucionalizar ações preservadoras das condições ideais de equilíbrio, uma vez que estas escapam à pura esfera de ação da natureza.

Tentaremos, neste pequeno ensaio, examinar brevemente cada um desses contextos conceituais, visando a descobrir os principais pontos de conflito e sugerindo eventuais conciliaçóes com o propósito de contribuir para a maior objetividade das discussões em torno da questão ambiental.

\section{Ecologia}

Existem dois critérios básicos para a abordagem da relação homem/natureza: o científico e o ético. A ecologia, como ciência biológica por excelência, não se preocupa com os aspectos éticos, uma vez que estes não fazem parte do patrimônio genético que qualifica as ações de sobrevivência biológica das espécies vegetais ou animais. A essência das relações intra e interespecíficas fundamentais à preservação da vida, dos ecossistemas e de certas espécies em particular (animais sociais) não é de natureza ética, mas se acha solidamente vinculada a uma estrutura gênica criada e organizada através de mutações e seleção ao longo da história evolutiva da espécie, sendo, em princípio, a única, nas atuais circunstâncias, (no sentido lamarquiano do termo) capaz de garantir a sua sobrevivência. Assim, não podemos comparar, por exemplo, o comportamento das formigas operárias de um formigueiro de saúvas, empenhadas durante toda sua vida no cultivo de fungos para o suprimento alimentar das larvas da colônia, com a atitude deliberada (e opcional) de um pai de família trabalhando (ou não) pelo sustento de seus filhos.

A biologia exclui, pois, do âmbito de suas cogitações, os comportamentos ético, moral, religioso ou político (aliás, os valores morais são puramente formais, segundo Kant, não sendo passíveis de ter sua universalidade assegurada através da experiência, o que, por si, afasta a possibilidade de seu tratamento dentro da metodologia científica biológica). Por conseguinte, a sua abordagem ecológica é isenta de qualquer consideração com relação ao sentimento de dever, característico da moral humana. Ela se contenta, ao contrário, com a análise das relações de dependência entre espécies ou entre estas e o meio, originadas de contingências orgânicas e físicas, sem as quais não seria possível a sobrevivência; ou, quando muito, das soluções alternativas não utilizadas pelo processo de seleção natural e das razôes de suapreferência. Os destaques empregados nos termos e expressóes acima são, justamente, significativos da ausência de intencionalidade ou de livre arbítrio que, em várias medidas, presidiriam as preferências éticas. 
A ecologia surgiu como uma quarta dimensão do estudo da biologia. A primeira, quase intuitiva, é a morfológica. As mais remotas povoações humanas já se preocupavam com a descrição, a representação, a classificação e, eventualmente, com significados esotéricos das formas animais e vegetais, daí se originando a anatomia e a sistemática. A segunda, fruto de curiosidade mais recente a respeito do funcionamento dos artefatos mecânicos e dos princípios que regem o movimento, é a que poderíamos denominar fisiológica, abrangendo um campo bastante amplo, de contornos indeterminados, a que os biólogos, em seu jargão cotidiano, costumam designar vagamente por biologia das espécies, a qual inclui os seus hábitos reprodutivos e aspectos do seu comportamento individual.

Uma terceira dimensão surgiu da necessidade intrínseca do conhecimento das origens, introduzindo o fator tempo nas preocupações biológicas, o que ensejou os estudos relativos à história dos organismos. Como foi reconhecido que essa história é feita de uma sucessão de estágios (geralmente tendendo a aumento de complexidade estrutural e funcional) correspondente a modificaçóes de caráter cíclico ou acíclico, contínuo ou descontínuo das características locais ou globais do Planeta, caracterizou-se essa história como sendo um processo evolutivo.

Finalmente, a própria pressão exercida por esses fatores em modificação sobre estruturas e comportamentos orgânicos, exigindo sua adequaçáo para que fosse possível a sobrevivência e denunciando estreita correlação morfofisiológica e comportamental entre as espécies e o seu meio, sugeriam a existência de uma quarta dimensão do estudo biológico, que seria a do conhecimento dos fatores externos determinantes e das acomodaçóes correspondentes, de ordens morfológica, fisiológica e comportamental, necessárias ao permanente ajustamento. Esse tipo de preocupação associava-se a outra indagação, mais antiga, relativa às evidentes diferenças existentes entre floras e faunas de diferentes regióes geográficas. A ecologia pode, assim, desde o seu princípio, compreender duas ênfases metodológicas principais: uma mais estática, correspondente à explicação de fatos e constataçôes relativas à geografia das espécies; outra, mais dinâmica, relacionada com a natureza dos mecanismos que levaram (ou levam, ainda hoje) às adaptações chamadas ecológicas. Humboldt foi, possivelmente, o primeiro a desenvolver uma pesquisa metódica dessas relaçóes estáticas entre organismos e meio ambiente, procurando criar não só metodologias de estudo geográfico como, também, de análise dos fatores físicos e químicos determinantes dessas diferenças geográficas. Ernst Haeckel, mais tarde, já familiarizado com os princípios da seleção natural como fator evolutivo, entregou-se aos aspectos mais dinâmicos da ecologia, tendo, inclusive, sido o autor da denominação.

As preocupações de ordem estática deram origem, principalmente, às metodologias autoecológicas, limitadas à constatação das inter-relações espaciais entre as espécies (representadas por um ou poucos espécimes) e o meio que as 
circunda. O estudo dinâmico, incluindo alternativas teóricas, fluxos de massa e de energia em um sistema como unidade morfológica e funcional, deu origem à sinecologia, em que as populaçốes (e não os indivíduos) passam a ter relevância metodológica.

A bibliografia biológica é extremamente rica de informações oriundas das observaçóes naturalísticas, quer no ambiente natural, quer no recinto de laboratórios, reunindo aspectos comportamentais (que se costuma distinguir com a denominação de etologia) e de relacionamento com os meios físico e biológico. Essas observações constituem a base de quase todo o conhecimento que se possui das relações específicas entre organismo e meio, na verdade, indispensáveis à compreensão dos ecossistemas. Se é verdade que o computador passou a constituir uma ferramenta quase indispensável ao ecólogo moderno, não é menos verdade que este não pode dispensar o seu microscópio, sob pena de passar a trabalhar apenas sobre números e não mais sobre seres vivos...

O modelo de Schrödinger para explicar o fenômeno biológico baseia-se, como se sabe, em relações de natureza puramente energética, o que, se por um lado eliminou barreiras à compreensão dos processos, reduzindo-os a meros fenômenos (embora peculiares) explicáveis pelas leis da física, dispensando o recurso às hipóteses vitalistas que exigiam a intervenção de forças e agentes de natureza desconhecida, por outro lado uniformiza excessivamente os processos ao reduzi-los a simples questão de demandas e disponibilidades gerando fluxos energéticos sempre que existam gradientes favoráveis, o que não é necessariamente verdadeiro.

Para Schrödinger, o ser vivo é um consumidor de entropia negativa, o que equivale dizer que ele consome ordem, ou seja, o papel da energia que flui através dos organismos é, principalmente, o de ordenar elementos retirados do meio ambiente. Diz ele que pensar como propriedade fundamental do ser vivo a simples troca de matérias ou de energia com o meio é absurdo. "Para um organismo adulto - afirma - o conteúdo energético é tão estacionário quanto o conteúdo material. Como, incontestavelmente, uma caloria vale tanto quanto outra qualquer, não se entende como uma simples troca poderia caracterizar o fenômeno vital" (Schrödinger, 1986).

Esse conceito, estendido à sinecologia, leva à compreensão fundamental dos ecossistemas como simples estruturas facilitadoras de fluxos de energia ordenadora na natureza (Lamarck, 1988, em um livro talvez menos conhecido do que deveria ser, define a natureza como uma ordem de coisas). Entretanto, não leva em conta especificidades das espécies vivas, indispensáveis às ordenaçôes especificas. Mutatis mutandis, estas especificidades são ilustradas, de maneira pitoresca, na fábula de La Fontaine, em que a cegonha é convidada pela raposa a tomar sopa 
em um prato raso e, no revide, esta é instada pela primeira a comer o alimento colocado no fundo de uma ânfora de colo longo... Não basta a energia (sob forma de alimento orgânico, ou mesmo de energia radiante direta) estar disponível: é necessário que existam os equipamentos físicos e bioquímicos habilitados a utilizar o seu potencial ordenador. É indispensável, em última análise, a existência de uma geometria que compatibilize as estruturas físicas e bioquímicas da espécie com as do substrato ambiente, para que essa ordenação e essa incorporação sejam possíveis (Branco, 1989).

Tais considerações podem ter importância prática, com relação aos estudos ambientais, no sentido de alertar, por exemplo, para o risco que existe em certas futurologias baseadas nas condiçöes potenciais de povoamento de algumas áreas.

A própria existência; verificada, de espécimes animais em determinada parcela ambiental pode não ser suficiente para atestar a sua viabilidade, pois podem não existir, por exemplo, condições específicas à sua reprodução ou a outras necessidades vitais. É o estudo autoecológico da região e das espécies que a habitam que permitirá a verificação dessa suposta viabilidade.

\section{Filosofia}

A ciência se fundamenta em hipóteses e a formulação da hipótese é um ato filosófico; o ato científico é subseqüiente, e consiste na definição de um método e na comprovação da hipótese.

A hipótese fundamental da ciência ecológica é a de que nenhum ser vivo tem existência independente dos demais e do meio físico. Essa hipótese leva à compreensão sistêmica da natureza, baseada na solidariedade intrínseca, e necessariamente dinâmica, entre todos os elementos que a compóem. Recorrendo ao modelo de Schrödinger, esses elementos acham-se intimamente ordenados, de modo a assegurar mínima geração de entropia ao longo das sequiências de transformaçóes materiais e energéticas que se operam no sistema. Os seres vivos, seus componentes, têm, assim, cada um deles: uma estrutura física (morfologia), uma atividade (fisiologia), uma história (evolução) e um relacionamento com o meio, caracterizado principalmente por um fluxo de entropia negativa (ecologia). Toda a metodologia desenvolvida na pesquisa ecológica - auto e sinecologia - busca evidências e valores que comprovem essa hipótese fundamental.

O homem é incluído nesse modelo como elemento perturbador. De início, ele compromete a hipótese fundamental em sua especificidade. Se ele não tem existência independente do meio, no sentido global, por outro lado libertou-se de dependências específicas com tais ou quais espécies animais, vegetais 
ou minerais. Suas exigências resumem-se, cada vez mais, aos elementos químicos simples e à energia, em qualquer de suas formas, pois a geometria necessária ele a constrói.

O homem necessita de alimento - obtido do meio - como fonte de entropia negativa; ele utiliza enzimas próprias (aliás, um complexo equipamento bioquímico) como mecanismo ordenador de elementos, tal como qualquer outro ser vivo (deixemos de lado os vírus). Nesse sentido, ele renunciou apenas à especificidade, pois dispóe (ou criou) dispositivos que o liberaram da exigência de uma mais estreita compatibilidade com o meio em que vive. É um elemento versátil, schrödingeriano, se for permitido o neologismo, nos fluxos de entropia negativa que caracterizam a natureza: ele escolhe $o$ ambiente em que deseja viver. Se isso é veŕdadeiro, em certa medida, para outros animais ditos onivoros, no caso humano atinge extremos muito mais amplos, pois ele pode processar tecnologicamente os compostos químicos.

No que diz respeito, porém, a outras dependências do meio, além da nutrição, ou seja, as relações de reprodução e proteção (que, para as demais espécies, também exigem uma geometria própria) o homem liberou-se completamente das contingências ambientais. Ele se apropria do meio e de seus componentes específicos transformando-os nos elementos que convencionou como sendo obrigatórios para a sua vida estática e dinámica, isto é, sua atividade biológica e de desenvolvimento, que é uma forma artificial de evolução.

Além das necessidades puramente biológicas - das quais a espécie humana ainda não conseguiu se liberar - o homem introduziu, portanto, outras necessidades, correspondentes aos conceitos de conforto e de desenvolvimento, o primeiro em nível mais individual e o segundo em nível coletivo ou social, mas não genérico, porque é amplamente variável com o fator cultural de cada sociedade.

Esses dois conceitos, ou melhor, as duas exigências básicas da sociedade humana compreendidas por esses conceitos, constituem duas reivindicaçōes a mais, a serem atendidas pelos recursos ambientais, além daquelas que compõem as exigências normais da totalidade das espécies vivas, exercendo, pois, uma pressão adicional, de intensidade significativa, sobre as estruturas e elementos componentes dos ecossistemas. Tais reivindicações cresceram e se diversificaram em um período de tempo extremamente curto e incompatível com a velocidade dos processos adaptativos normais, históricos, ocorridos desde a formação da Terra, assumindo feições de cataclismo ambiental: elas não correspondem a verdadeiras alteraçốes espontaneas da composição e da estrutura física dinâmicas da biosfera. Por conseguinte, não podem ser atendidas sem que se produzam fortes desbalanceamentos das relações materiais e energéticas dos ecossistemas. 
Escapando, portanto, ao âmbito dasprovidências, de caráter adaptativo, que poderiam estar a cargo da própria natureza (como entidade personificadora das chamadas leis naturais), a manutenção do desejado equilíbrio, imprescindível à conservação das espécies e, principalmente, da estrutura morfológica e funcional dos ecossistemas, só pode ser realizada por deliberação explícita do próprio homem, uma vez que este assumiu, por assim dizer, as rédeas do processo. E é nisso que se fundamenta o princípio ético a orientar o comportamento moral do homem com relação à natureza.

Os filósofos - embora utilizando diferentes formas de expressão - são unânimes em admitir que a moral é resultante de um sentimento de dever e, portanto, é exclusiva do ser humano. Ela substitui, neste, as imposiçóes da natureza que regulam o comportamento, por exemplo, das sociedades de insetos. Num formigueiro, segundo Bergson (1984), há uma regra necessária e não uma obrigação, pois esta pressupõe liberdade de escolha; nas sociedades humanas, ao contrário, só uma coisa é natural: a necessidade de uma regra, para que essa sociedade se mantenha. "O domínio da moral é o domínio do dever - afirma Durkheim 1992) - e o dever é uma ação prescrita", no que concorda com Kant que afirma ser o bem moral sempre interessado, tendo em vista sempre uma recompensa ou um castigo (antes ou após à morte), só possuindo conteúdo formal, como já foi aqui mencionado (Kant, 1959).

Mesmo formal, a moral é indispensável à sobrevivência das sociedades humanas, e a sua base são os deveres. Isentos de deveres são só os animais e os deuses - prescreve o filósofo contemporâneo Delattre (1991) -: os primeiros, por serem objeto do determinismo da natureza; os deuses, por estarem, por definição, acima de todas as regras.

Mas esses deveres - ou obrigaçôes - são atos (espontâneos ou não, racionais ou não) de submissão do homem à sociedade e não à natureza. Durkheim (1992) enfatiza bem a questão: "portanto, os fins morais são aqueles que têm por objeto uma sociedade" e estende-se longamente sobre o assunto. Bergson (1984) dilata um pouco a sua extensão, afirmando: "poder-se-ia dizer que a segunda moral - se decididamente nós distinguirmos duas - difere da primeira por ser humana, em lugar de ser somente social" e acrescenta, logo a seguir, que a diferença entre uma moral humana e uma moral social não é apenas de grau, mas de natureza. Trata-se de um dever humano, resultante de uma dilatação do dever social: uma espécie de devotamento, mais que uma simples obrigação natural, devotamento que se traduz em amor pela humanidade, mas não fala em amor pela natureza... O próprio Lamarck, - o naturalista - naquela sua curiosa obra já citada, (a qual é mencionada por Freud, pela influência que teria nele provocado), também fala, enfaticamente, das obrigações morais com relação ao interesse da sociedade, silenciando, igualmente, sobre deveres intrínsecos para com a natureza 
(Lamarck, 1988). Finalmente, Kant (1959) enuncia seu famoso imperativo categórico, regra básica da conduta moral, complementada pela afirmação de que, em todas as nossas ações, o homem deve constituir o objeto final.

Diante dessas limitações conceituais, torna-se, pois, lícito indagar sobre a legitimidade de uma ética fundamentada em deveres para com a natureza, em oposição a uma ética baseada em deveres para com o gênero humano. Em outras palavras, até que ponto se extenua o dever moral com relação à proteção à natureza por si mesma e não pelo prejuízo ao ser humano que pode decorrer da sua destruição ou simples alteração?

"A lógica da obrigação social - diz Delattre (1991), baseado, entre outros, no Contrato Social de Rousseau - é a lógica da reciprocidade". A invocação de direitos implica, necessariamente, relação entre elementos de mesma espécie. Do contrário, tratar-se-ia de simples peculiaridades. Os direitos que cada um possui com relação à sociedade decorrem de deveres dos membros da sociedade com relação a cada um dos outros membros. Pode uma espécie animal ou vegetal ter deveres para com a sociedade humana? ( $O$ dever do porco tornar-se presunto...?) Por que não é considerado imoral matar-se um animal no matadouro? $\mathrm{Ou}$ destruir espécies daninhas, segundo o nosso ponto de vista? É a destruição em massa que é imoral? Neste caso, pode-se condenar o ato de ceifar um campo de trigo ou derrubar uma mata de eucalipto? Ou destruir um formigueiro? Não. Somente o comprometimento de um equilíbrio, à medida em que seja este indispensável à nossa sobrevivência e conforto. Trata-se, assim, de uma ética para com a própria humanidade.

A impropriedade da lei moral aplicada às coisas (coisa é tudo o que não pode ser objeto de imputação, segundo Kant (1952) transparece já na tendência que todos nós possuímos a cercar de maiores cuidados e carinho os seres que nos parecem particularmente belos, como as borboletas e os pássaros, independentemente dos danos que possam causar, desprezando os mais feios, como morcegos, aranhas e escorpiões, apesar de nos livrarem de muitos incômodos e danos, o que leva à dúvida expressa por Platão, no Górgias, sobre se o belo é, necessariamente, bom. Disso depreende-se a impossibilidade de se estabelecer leis objetivas de proteção aos elementos da natureza. Estas só podem ser praticadas quando se referem, bastante vagamente, ao seu equilíbrio geral, o que torna excessivamente problemática a sua aplicação.

Ferry (1992), filósofo contemporâneo, abordou esta questão, estendendose longamente, do ponto de vista do estatuto de direito dos animais, vegetais, acidentes geográficos e outras entidades destituídas de personalidade jurídica, em face da tendência manifestada por muitos partidários dos movimentos ecológicos, de atribuir-lhes tal estado de direito. Na Idade Média e até o final do século 
XVI, eram freqüentes, na Europa, os processos movidos contra animais que constituíam pragas da lavoura ou que, de algum modo, interferiam na vida e no conforto das populaçôes humanas. Ferry relata alguns desses episódios ocorridos na França, como por exemplo, ação promovida por agricultores contra a invasão de suas vinhas por carunchos ou a infestação de um lago por sanguessugas. Tais petiçóes eram dirigidas ao juiz episcopal local, o qual instituía processo, designando advogado ad-hoc para defesa dos acusados etc. Finalmente, como conclusão do processo, as pragas, se consideradas culpadas, eram condenadas e obrigadas a mudarem-se em um prazo estipulado ou, no caso de desobediência, eram excomungadas. Em muitos casos, porém, a defesa conseguia demonstrar a inculpabilidade dos animaizinhos (pelo direito que tinham à vida, como criaturas de Deus) e, então, os peticionários eram condenados a penitências e procissóes ou a oferecer ao réu, local agradável para onde pudessem transferir-se. Ferry menciona esses casos como exemplos que caracterizam um estatuto de pessoas jurídicas, desses animais, semelhante ao que pretendem, hoje, alguns grupos ambientalistas radicais, estender a todas as coisas da natureza.

Os processos da Inquisição, durante a Idade Média, aliás, nem sempre levavam em conta a ausência de responsabilidade ou incapacidade de resposta, que caracteriza, por sua vez, a falta de reciprocidade, recomendada por Rousseau, entre o indivíduo e a sociedade. Condenavam, assim, à fogueira, tanto o herege consciente quanto uma pessoa mentalmente incapaz, ou um galo que, por acidente, botava um ovo... $\mathrm{O}$ argumento era o de que esses seres abrigariam espíritos maléficos e, como tal, deveriam ser eliminados do nosso convívio, mesmo que fossem meros instrumentos inconscientes. Mas, nos casos citados anteriormente, essa responsabilidade era cobrada aos carunchos e sanguessugas, tanto assim, que eram intimados a comparecer em juízo, pessoalmente ou representados por um advogado. Só no caso de não comparecerem à audiência marcada, por si ou por seu representante, é que a autoridade eclesiástica nomeava o advogado adhoc, marcando nova audiência.

Há uma diferença substantiva que, entretanto, não foi considerada pelo filósofo Ferry no caso do argumento de irresponsabilidade. Exige-se a responsabilidade no caso do julgado ser réu e não vítima. No caso contrário, evidentemente, a capacidade mental não é exigida, pois, se assim fosse, as crianças, os senís e os doentes mentais não mereceriam a proteção da lei. Por outro lado, entretanto, as pessoas mentalmente incapazes pertencem, de qualquer forma, à sociedade humana o que parece confirmar ser esta, realmente, a condição fundamental para a extensão do conceito ético.

De qualquer forma, a inclusão ideal de seres estranhos à sociedade humana, ao âmbito das nossas restriçóes e deveres morais traria dificuldades práticas e teóricas intransponíveis. Em primeiro lugar, pela impossibilidade de uma 
hierarquização adequada que, fatalmente, incluiria forte dose de subjetividade. Muitas pessoas que adotam a alimentação vegetariana, por uma questão humanitária, não comem carne de mamíferos e aves, mas sim peixes; e têm dúvida sobre répteis (tartarugas, por exemplo) ou anfíbios (rãs). Algumas populações, na América Latina, por respeito à abstinência na quaresma ou na Semana-Santa, não comem carne de boi, porco ou aves, mas não fazem qualquer restrição à carne de capivara, por ser um animal de hábitos aquáticos (na Venezuela, onde esses roedores são criados comercialmente, os açougues os vendem em grande quantidade nesses períodos de continência religiosa....).

Em segundo lugar, há a questão da necessidade eventual do desbaste de populaçóes, quando estas se desenvolvem excessivamente em consequiência, às vezes, das próprias medidas de proteção adotadas. Impalas e outros antílopes, no Quênia, assim como algumas espécies de cangurus, na Austrália, necessitam controle de suas populaçôes - independentemente da sua beleza ou fragilidade mediante abertura de temporadas de caga específicas.

Finalmente, há o problema, bastante complexo, da incompatibilidade de algumas espécies com o homem. Não se pode pensar em proteger o vírus da Aids, o plasmódio da malária, ou os protozoários causadores da úlcera de Bauru, ou da doença de Chagas, por serem seres vivos (inclusive, os últimos, são, esteticamente, muito elegantes e bonitos, embora microscópicos...). Mesmo a argumentação de que se trata de seres que, normalmente, são parasitas de macacos, tatus e gambás, tais argumentos não convencerão os mais radicais ambientalistas a poupá-los. A mesma coisa ocorre com relação aos gafanhotos, aos camundongos e a uma infinidade de espécies - animais e vegetais - considerados nocivos, em suas relações com o homem. Acrescente-se que, muitas vezes, os animais em questáo são exterminados apenas por serem portadores do parasita, como é o caso dos indefesos caramujos que transmitem a esquistossomose. A questão se torna ainda muito mais complexa quando lembramos que algumas dessas pragas - principalmente vegetais - poderão revelar-se, no futuro, produtoras de princípios ativos de valor farmacológico talvez decisivo na cura de alguns dos flagelos que assolam a humanidade...

Todas essas questóes são, evidentemente, subjetivas, exigindo atitudes e definiçõos convencionais para cada caso, o que impossibilita o estabelecimento de leis gerais baseadas em fundamentos de ordem moral. Não pode haver uma moral que determine o extermínio dos gafanhotos e carunchos e, ao mesmo tempo, a proteção às borboletas de asas vistosas e coloridas, a não ser que essa moral tenha em vista, precipuamente, o homem e não a natureza.

A discriminação convencional de certas espécies, como preceito moral, leva à sacralizaçáo de alguns seres da natureza e, portanto, à atitude religiosa, tendo 
sempre o homem, a sua sobrevivência, o seu conforto físico e espiritual, como objetivo central. Um dever para com a natureza ou é compreendido como um dever para com o próprio homem (dados os benefícios que, da proteção à natureza, resultam para o ser humano) ou é de natureza mística, fruto de uma tendência, também exclusivamente humana, de sacralizar tudo o que afete mais ou menos profundamente as suas convicções e visão do mundo. Isso ocorre principalmente quando essas alterações de conviç̧ão provêm não de demonstrações empíricas tangíveis, mas sim de concepçóes universalistas que escapam ao poder da prova concreta e imediata. Principalmente os fatos e fenômenos que dizem respeito à natureza, sempre constituíram mistérios que o homem procura resolver através de soluçóes e conceitos místicos, fora do compreensível, invocando forgas da natureza, de caráter metafísico, tais como a força vital, necessária à explicação, outrora, da síntese dos compostos orgânicos, da diferenciação de células embrionárias e de outros fenômenos cuja explicação física não era evidente. Assim, um dever para com a natureza surge como uma atitude de prudente submissão religiosa a leis (ou totems) que estejam acima da nossa compreensão, em lugar de um simples compromisso ético para com a nossa sociedade. Ainda assim, porém, trata-se de atitude que, em última análise, visa à proteção atual e futura do próprio homem e da humanidade como um todo.

\section{Sociologia}

Existe, realmente, uma ecologia humana? Ou esta pode ser reduzida à sociologia? São duas perguntas que, recentemente, nos foram dirigidas pelo amigo e mestre Erasmo Garcia Mendes, em agradável reunião na USP.

O desafio é grande e, por isso mesmo, sedutor. Vejamos como poderá ser, pelo menos, encaminhada uma resposta, tendo em vista, em primeiro lugar, o conceito, mesmo, de ecologia, ou seja, de estudo das relações de interdependência entre os seres vivos e o meio, ou, numa definiçáo mais moderna e sinecológica, estudo da estrutura e função da natureza (Odum, 1969). Nesta última definição, o ser vivo é visto como um participante obrigatório dos fluxos de energia e matéria numa natureza em equilíbrio dinâmico.

Consideremos, em seguida, uma definição corrente de sociologia: estudo das formas de organização dos grupos sociais, dos tipos de relação que mantêm entre si e da influência que exercem sobre o comportamento dos indivíduos que deles fazem parte. É como se fosse o estudo das relações que mantêm, entre si, os grupos heterogêneos que compóem um ecossistema, porém independente do meio em que vivem. Em última análise, é o fato de se tratar de populaçóes homogêneas (uma só espécie) e, principalmente, de grupos sociais e suas relações serem estudados independentemente de eventuais relações com o meio físico, que serve de distinção entre os dois conceitos. 
Entretanto, analisemos a questão de um outro ângulo: existe uma ecologia das espécies de animais sociais, como formigas e abelhas? Sim, sem dúvida; suas colônias, como um todo, fazem parte da estrutụra e função da natureza, desempenhando um papel no seu equilíbrio dinâmico. Existe, por outro lado, uma verdadeira sociologia, desses insetos? Parece que não; as definiçóes citadas de sociologia implicam uma certa flexibilidade do comportamento individual com relaçăo à sociedade; do contrário, não existiriam influências dos grupos sobre o comportamento dos indivíduos. Essa flexibilidade não existe nas sociedades organizadas das formigas. As suas relações sociais são imutáveis.

Além disso, o homem - seja isolado, seja em sociedade - não se vincula a qualquer cadeia de alimentaçáo ou fluxo de energia/matéria, na natureza, isto é, não participa de sua estrutura e função: apenas interfere nelas. A atividade humana consiste em introduzir novas orientaçōes aos fluxos energéticos e de massa, no sentido de dirigi-los para proveito de suas comunidades, e este é o seu modo característico de relacionar-se com o meio ambiente. O equilíbrio de suas sociedades é de natureza sociológica e não ecológica. O seu próprio meio ambiente é artificial, criado visando a um fim social. Ele se beneficia do equilíbrio ecológico natural, mas não participa dele. $O$ estudo das relações entre o homem e o seu meio cabe à sociologia e não à ecologia. Como muito bem qualifica o filósofo e sociólogo José de Ávila Coimbra (comunicação pessoal), o ambiente humano e seus processos podem ser análogos, mas não iguais aos que caracterizam o meio natural.

É comum dizer-se que a ecologia é o único ramo da ciência que se tornou movimento político. É um engano. A ecologia, tal como foi aqui definida, não constitui a base de um movimento político. Este, nasceu, antes, de um movimento de natureza ética, visando a proteger a espécie humana contra uma ação por demais predatória que se vem desenvolvendo contra a natureza. Já ocorreram, anteriormente, movimentos do mesmo tipo, invocando os conceitos da física nuclear e da induçáo radiativa, contra a ameaça da guerra nuclear e, atualmente, movimento - também ético - inicia-se contra o mau emprego da genética. $O$ erro, no caso em apreço, está em se ter batizado tais manifestaçóes políticas com o nome de uma ciência, como se fossem sinônimos. As denominações de movimento ecológico, ou partido ecológico, assim como de ecologistas aos seus partidários, gera, inevitavelmente, algumas confusóes, às quais não souberam furtar-se, inclusive, eminentes pensadores, como o filósofo Luc Ferry, ao caracterizar como "as três ecologias", três diferentes abordagens políticas dos problemas ambientais, sem sequer mencionar, em momento algum a existência de uma ciência ecológica (Ferry, 1992). Melhor seria, sem dúvida, o emprego dos termos ambientalismo e ambientalista para designar tais movimentos e seus partidários. Antes de tudo, esses partidos reivindicam melhor qualidade de vida para o ser humano, expressão que aproxima a defesa ambiental das reivindicações sociais. 
A aplicação pura e simples dos conceitos ecológicos às relações sociais, como se pudessem ser tomados como conceitos sociológicos, tem levado a alguns erros muito graves. Isso já aconteceu, antes, quando se pretendeu aplicar às sociedades humanas atuais, as definições de Darwin a respeito do princípio da seleção natural, originando uma noção altamente elitista a que se deu a denominação de darwinismo social. Agora, tendo-se em vista que nas relações ecológicas, considera-se altamente salutar, considerando-se a estabilidade dos ecossistemas, a diversidade de espécies, questiona-se se esse mesmo princípio, aplicado aos grupos étnicos humanos não estaria em contradição com os princípios humanísticos, defendidos desde a Revolução Francesa, de igualdade entre os seres humanos (Ferry, 1992).

Há evidente equívoco nesta preocupação que é, de um lado, o pensar-se que a preservação de grupos culturais humanos tem o mesmo sentido da preservação de grande diversidade de espécies vegetais e animais. Estas, segundo demonstrou Darwin, são produtos de uma seleção natural e representam uma reserva potencial de possibilidades de adaptações a ambientes em constantes transformações, enquanto que os grupos étnicos representam uma só espécie, com adaptaçôes culturais a diferentes regiōes do globo. De outro lado, o direito à diferença, que se procura preservar entre os diferentes povos, é opcional e não fere os direitos fundamentais humanos, como o fariam as discriminações racistas e políticas autoritárias.

\section{Conclusão}

A primeira grande dificuldade que transparece neste pequeno ensaio de caracterização dos problemas ambientais decorre do caráter interdisciplinar da matéria. Isso torna difíceis a abrangência dos problemas por um só especialista, o entendimento entre diferentes profissionais, pela inexistência de uma metodologia interdisciplinar, e a própria formação de equipes de estudos e de ensino, dada a tradicional dificuldade de entrosamento entre diferentes departamentos do saber acadêmico... Uma abordagem, ao mesmo tempo, filosófica, sociológica e biológica, com implicaçôes econômicas e políticas de um mesmo problema e da qual resulte um trabalho perfeitamente equilibrado e entrosado, com conclusões perfeitamente consensuais e compatíveis é coisa humanamente impossível de conseguir-se. Certamente ocorrerão incoerências, contradiçôes e imposições de conceitos. Assim sendo, possivelmente nunca se disporá de uma doutrina consistente e uniforme a ser apontada como averdadeira ciência do meio ambiente para uso nos debates sobre impactos ambientais ou em cursos de formação de profissionais para sua avaliação.

Entretanto, no sentido de contribuir objetivamente para a edificação dessa suposta doutrina, alguns aspectos resultantes da análise precedente podem ser 
relevantes para a abordagem das conseqüências da presença do homem como elemento perturbador do equilíbrio natural dos ecossistemas.

O homem pertence à natureza tanto quanto - numa imagem que me parece apropriada - o embrião pertence ao ventre materno: originou-se dela e canaliza todos os seus recursos para as próprias funções e desenvolvimento, não lhe dando nada em troca. É seu dependente, mas não participa (pelo contrário, interfere) de sua estrutura e função normais. Será um simples embrião, se conseguir sugar a natureza, permanentemente, de forma compatível, isto é, sem produzir desgastes significativos e irreversíveis; caso contrário, será um câncer, o qual se extinguirá com a extinção do hospedeiro...

Essa compatibilidade necessária do homem-parasita com a naturezahospedeira envolve, como foi visto, demandas não apresentadas por qualquer outro ser vivo, as quais correm por conta de um conceito de bem-estar particular, da espécie, que inclui as noções de conforto e de desenvolvimento. Não sendo usuais, essas demandas não poderiam ser supridas através dos canais energéticos e materiais normais, tornando necessário o desenvolvimento de alternativas tecnológicas, em substituição ou em reforço às formas correntes de atendimento. Isso é possível, em princípio, porque a fonte de energia principal não tem a sua capacidade esgotada (ou esgotável, mesmo a longo prazo), embora seja necessária parcimônia no uso das matérias elementares indispensáveis à sua conversão e utilização. Graças a esse novo tipo de entrosamento entre o homem e a natureza, aquele passaria, de simples usuário/explorador, a partícipe de uma relação de troca, principalmente no que tange aos ciclos materiais. Nisso repousaria, essencialmente, a desejável situação de compatibilidade, semelhante à que existia antes da era industrial, quando as demandas eram muito menores.

As ações de natureza legal-institucional e os movimentos sociais ambientalistas têm, como base, o dever moral para com a sociedade de manter o equilíbrio apontado, por ser vital à sua sobrevivência. Em última análise, são ações que visam, acima de tudo, à melhor qualidade de vida para a espécie humana como um todo. Em alguns desses movimentos, podem-se configurar caracteres extremos de religião ou de opção político-partidária, em que as delimitações lógico-conceituais freqüentemente se perdem, em favor de simples ideologias místico-idealistas, às vezes até visionárias invadindo os limites do fanatismo que, segundo Delattre (1991), constitui uma espécie de paixão pelo dever.

A necessidade geral de preservação dos elementos componentes da nature$\mathrm{za}$, para que não se extingam, ou para que não se desfaça o equilíbrio dos ecossistemas, pode derivar de uma compreensão cientifica do problema ou de um dever ético para com a sociedade, embora este não decorra necessariamente daquela. No primeiro caso, todas as espécies e ecossistemas estarão abrangidos, 
independentemente da eventual utilidade ou do prejuízo que possam causar às comunidades humanas (um elefante ou um escorpião; um deserto natural, um pântano ou uma floresta tropical terão igual valor e mérito). No segundo caso, só serão compreensíveis as providências visando à preservação de espécies ou relações úteis, no seu mais amplo sentido: inclusive aquelas que são objeto da atenção dos cientistas, como fatores de possíveis benefícios futuros à espécie humana.

Uma hierarquia de espécies a serem protegidas é impossível de ser realizada de forma objetiva. Apenas há a possibilidade de estabelecimento de regras que visem a salvaguarda do equilíbrio geral dos ecossistemas, tendo em vista, precipuamente, o homem e não a natureza, no sentido amplo já enunciado.

A avaliação do equilíbrio de um ecossistema não pode ser sempre feita a partir de simples estudos de demandas e disponibilidades energéticas e materiais. É necessário, com freqüência, considerar-se os detalhes autoecológicos presentes. Assim, não é possível, por exemplo, estabelecer-se a viabilidade de uma espécie em determinada área, apenas em termos potenciais.

A análise dos impactos ambientais produzidos por um empreendimento de alegada utilidade tem em vista obter o máximo benefício, com o mínimo custo ambiental e não um beneficio sem custo, pois não existe intervenção sem trauma, ou obra sem custo.

\section{Referências bibliográficas}

BERGSON, $\mathrm{H}$. Les deux sources de la morale et de la religion. Presses Universitaires de France. 218a ed., 1984.

BRANCO, S. M. Ecossistêmica - uma abordagem integrada dos problemas do meio ambiente. Edgard Blücher, 1989.

DELATTRE, M. Le devoir. Éditions Quintette, 1991.

DURKHEIM, E. L'éducation morale. Presses Universitaires de France. 1992.

FERRY, L. Le Nouvel ordre écologique - l'arbre, l'animal et l'homme. Éditions Grasset \& Fasquelle, 1992.

HUMBOLDT, A. Viaje a las regiones equinocciales del nuevo continente. 5 V. Monte Avila Latinoamericana, 1991.

KANT, I. The critique of judgement. William Benton, Publisher, 1952. 
LAMARCK, J-B. Systeme analytique des connaissances positipes de l'homme. Presses Universitaires de France, 1988.

ODUM, E.P. Ecologia. São Paulo, Pioneira, 1969.

SCHRÖDINGER, E. Qu'est-ce que la vie? - De la physique à la biologie. Christian Bourgois (Éd.), 1986.

\title{
Resumo
}

Discute-se a relação homem/natureza do ponto de vista da ecologia, como ciência, e da ética. A ética subentende deveres para com a sociedade e não para com a natureza. Assim sendo, a obrigação moral de proteger a natureza tem em mente o bem-estar social e a melhor qualidade de vida humana. Nenhum princípio ético geral pode ser invocado para justificar a proteção indiscriminada a todas as espécies e ecossistemas. Entretanto, o sentido de utilidade, dos mesmos, para a espécie humana, deve ser tomado no seu mais amplo sentido, incluindo aqueles que são objeto da atenção dos cientistas, como fatores de benefícios potenciais à humanidade.

\begin{abstract}
In this paper the interaction man/nature from the ecological and ethical points of view are discussed. Ethics is related to the human societies and is not concerned with nature. In this way the human compromises with environment protection is restricted to the welfare of future generations. No ethical principle can be invoked to justify the indiscriminated protection to every species and ecossystems. However, the utility of the ecossystems and species must be taken in its largest sense including those which are object of interest for the scientists as benefical factors potentially useful for mankind.
\end{abstract}

Samuel Murgel Branco é professor titular (aposentado) da Faculdade de Saúde Pública da USP. É autor de 22 livros paradidáticos sobre meio ambiente dirigido ao público infanto-juvenil, entre eles Aventura de uma gota d'água (Editora Moderna), que encontrase na $35^{\circ}$ ediçãao. 